\title{
Platelet Activation Markers in Children with Pulmonary Arterial Hypertension Associated with Congenital Heart Disease
}

\author{
Abdulhalim Awad $^{1} \cdot$ Shimaa Elnemr ${ }^{1} \cdot$ Hossam Hodeib ${ }^{2} \cdot$ Doaa El Amrousy $^{1}$ (D)
}

Received: 21 December 2021 / Accepted: 7 February 2022 / Published online: 2 March 2022

(c) The Author(s) 2022

\begin{abstract}
The study aimed to evaluate mean platelet volume (MPV), platelet distribution width (PDW), and platecrit in children with pulmonary arterial hypertension associated with congenital heart disease (PAH-CHD), to assess the predictive value of these platelet activation markers for adverse outcomes, and to correlate their levels with various data in these patients. This prospective cohort study included 60 children with PAH-CHD as group I and 60 children with CHD and no PAH as group II. Another 60 healthy children of matched age and sex served as the control group. All included children were evaluated by echocardiography. MPV, PDW, and platecrit were also measured using an automated blood counter. All patients were followed up for death or readmission for 6 months. MPV, PDW, and platecrit were significantly higher in group I compared to group II and the control group and they correlated well with increasing severity of PAH. MPV, PDW, and platecrit positively correlated with right ventricular diameter and mean pulmonary artery pressure, however they correlated negatively with right ventricular systolic and diastolic function. The best cut-off of platelet activation markers levels to predict poor prognosis in group I was $>11.2 \mathrm{FL}$ with $75 \%$ sensitivity and $96.6 \%$ specificity for MPV, $>12.7$ FL with $75 \%$ sensitivity and $61.5 \%$ specificity for PDW, and $>0.505 \%$ with $75 \%$ sensitivity and $93.2 \%$ specificity for platecrit. MPV, PDW, and platecrit were elevated in children with PAH-CHD and found to be good predictive markers for poor prognosis in these children.
\end{abstract}

Keywords Pulmonary arterial hypertension $\cdot$ Congenital heart disease $\cdot$ Platelet activation markers $\cdot$ Prognosis $\cdot$ Predictive markers

\section{Introduction}

Congenital heart disease (CHD) accounts for nearly onethird of all major congenital anomalies [1]. Pulmonary hypertension $(\mathrm{PH})$ is a hemodynamic and pathophysiological disorder that defined as an increase in mean pulmonary

Doaa El Amrousy

doaamoha@yahoo.com

Abdulhalim Awad

mohamedkashlan@yahoo.com

Shimaa Elnemr

dr.shimaaelnemr@yahoo.com

Hossam Hodeib

hossamhodeib@gmail.com

1 Pediatric Department, Faculty of Medicine, Tanta University, Tanta, Egypt

2 Clinical Pathology Department, Faculty of Medicine, Tanta University, Tanta, Egypt arterial pressure $(\mathrm{mPAP}) \geq 20 \mathrm{mmHg}$ at rest as assessed by right heart catheterization [2-4].

One of the most important types of $\mathrm{PH}$ in children is pulmonary arterial hypertension associated with congenital heart disease (PAH-CHD) [5]. PAH-CHD is usually the result of a large systemic to pulmonary shunt, and often leads to right ventricular failure and early death $[6,7]$.

Several recent studies have suggested that the interactions between platelets and pulmonary arterioles can contribute to the progressive pulmonary vascular changes seen in PAH [8]. Mean platelet volume (MPV), platelet distribution width (PDW), and platecrit (PCT) are simple hematological markers of assessing platelet function and activation. MPV increases during platelet activation and reflects platelet production [9]. PDW directly measures the variability in platelet size and is a marker of platelet activation. PDW and platecrit also provide information on total platelet mass [10].

In situ thrombosis may contribute to the development and progression of PAH. Patients with PAH was reported to have increased platelet aggregation and activation [11]. 
Furthermore, MPV and PDW were found to be significantly high in adults with idiopathic PAH [12]. Also, MPV correlated with systolic pulmonary artery pressure and right ventricular diameter in patients with atrial septal defect [13].

Platelet activation markers has been studied in children with PAH-CHD in few studies and showed contradictory results $[14,15]$. So, we performed our research to evaluate platelet activation indices (MPV, PDW, and platecrit) in children with PAH-CHD and to evaluate their prognostic value for adverse outcome in such patients.

\section{Subjects and Methods}

This prospective cohort study was performed at the Pediatric Department, Tanta University, during the period from April 2019 to October 2020 on sixty children with PAH-CHD as group I and 60 children with CHD and no PAH as group II. Another 60 healthy children of matched age and sex served as the control group. The study was approved by the ethical committee of the Faculty of Medicine, Tanta University. Written informed consent was signed by all parents of the included children.

\section{Inclusion criteria Children less than 18 years with CHD with or without PAH. \\ Exclusion criteria Patients with chronic respiratory dis- ease, acute heart failure, pulmonary venous hypertension, platelet disor- ders, chronic liver or renal disease, and patients using antiplatelet or anticoagu- lant therapy.}

Detailed history taking and complete clinical examination including anthropometric measurements, heart rate (HR), respiratory rate (RR), signs of $\mathrm{CHD}$, signs of $\mathrm{PH}$, and complete local cardiac examination were recorded.

\section{Echocardiography}

The echocardiographic assessment was performed using the Vivid 7 ultrasound machine (GE Medical System, Horten, Norway) with 7 and $4 \mathrm{~s} \mathrm{MHz}$ multi-frequency transducers. Doppler, two-dimensional, and M mode were used for the assessment of the type of congenital heart disease and mPAP. mPAP was measured from peak pulmonary regurge (PR) Doppler signal obtained in the parasternal short axis view. Peak pressure difference (measured by the Bernoulli equation) is then added to the right atrial pressure (RAP). mPAP can be estimated using the following formula: $\mathrm{mPAP}=4$ (PR peak velocity) ${ }^{2}+\mathrm{RAP}$. Right ventricular systolic function was assessed using right ventricular fractional area change (RV FAC) by two-dimensional (2D) echocardiography from the apical four chamber view where $\mathrm{RV} F A C=\mathrm{RV}$ end-diastolic area $-\mathrm{RV}$ end-systolic area/RV end-diastolic area $\times 100$. Right ventricular diastolic function was measured through pulsed Doppler through the tricuspid valve in the form of tricuspid $E / A$ ratio where $E$ wave is the peak early filling velocity and $A$ wave is the peak late filling velocity [16]. Right ventricular diameter (RVD) was also measured.

Left ventricle end-diastolic diameter (LVEDD) and left ventricle end-systolic diameter (LVESD) were also measured. Left ventricle systolic function was assessed by LV fraction shortening $($ FS\% $)=($ LVEDD $)-($ LVESD $) /$ $($ LVEDD) $\times 100 \%$.

Mean platelet volume, Platelet distribution width, and platecrit were measured using an automated blood counter for blood tests and using blood collection tubes (Greiner Bio-one, Austria) containing K2-EDTA. Blood samples were analyzed within 15 min after collection to avoid possible errors caused by platelet swelling with EDTA.

Patients were followed up for 6 months for mortality and readmission to the hospital. Good prognosis was defined as no mortality or readmission to the hospital due to PAH-CHD during the period of follow-up, while poor prognosis was defined as death or readmission of the patients during the period of follow-up. PAH was classified as mild, moderate, and severe according to MPAP [17].

The primary outcome of this study was to assess platelet activation markers in children with PAH-CHD. The secondary outcomes were to assess the predictive values of platelet activation markers for adverse outcomes in children with PAH-CHD and to correlate platelet activation markers levels with various clinical, echocardiographic, and hemodynamic parameters in these children.

\section{Statistical Analysis}

Data were fed to the computer and analyzed using IBM SPSS software package version 20.0. (Armonk, NY: IBM Corp). Qualitative data were described using number and percent. Comparing qualitative data between the three groups was performed using $\chi^{2}$ test. The Kolmogorov-Smirnov test was used to verify the normality of distribution of the data. Normally distributed quantitative data were described using mean and standard deviation (SD). Abnormally distributed quantitative data were described using median and interquartile range. Comparing normally distributed quantitative data were performed using one way analysis of variance (ANOVA). Comparing abnormally distributed quantitative data were performed using Kruskal-Wallis test. Correlation between platelet activation markers and various clinical and echocardiographic data were performed using Pearson correlation test. Receiver operating characteristics (ROC) curve was drawn to assess the predictive value of various 
platelet activation markers to predict adverse outcome at different cut-off levels. Significance of the obtained results was judged at the $5 \%$ level.

\section{Results}

The study included 60 children with PAH-CHD with a median age of $5.5 \mathrm{~m}$; they were 32 male and 28 female. Children with CHD only had a median age of $3.5 \mathrm{~m}$; they were 40 male and 20 female. The healthy control group had a median age of $9 \mathrm{~m}$; they were 26 male and 34 female. There was no statistically significant difference between the three groups as regards age and sex. However, there was a significantly lower weight in children with CHD either with or without PAH compared to the healthy control. RR and HR were significantly higher in children with CHD with or without PAH compared to the healthy control group.

Platecrit was significantly higher in children with PAH-CHD $(0.36 \pm 0.13)$ compared to children with CHD (0.25 \pm 0.07$)$ and the control group $(0.20 \pm 0.06)$; $(P<0.001)$. MPV was significantly higher in children with PAH-CHD $(10.19 \pm 1.44)$ compared to children with CHD (8.80 \pm 0.73$)$ and the control group (8.42 \pm 0.98$)$; $(P<0.001)$. Similarly, PDW was significantly higher in children with PAH-CHD $(13.20 \pm 3.10)$ compared to children with CHD (9.88 \pm 1.39$)$ and the control group $(9.76 \pm 1.35)$; $(P<0.001)$. (Table 1$)$.

Table 2 shows that RV FAC and RV E/A ratio were significantly lower in CHD-PH compared to CHD group and the control group. There was an insignificant difference among the three groups as regards LV FS. mPAP and RVD were significantly higher in CHD-PH group compared to $\mathrm{CHD}$ group and the control group.

Platecrit, PDW, and MPV were significantly higher in patients with severe $\mathrm{PH}$ than those with mild and moderate PH. Platecrit, PDW, and MPV were comparable in children with mild and moderate PH (Table 3 ).

Table 2 Echocardiographic parameters in the studied groups

\begin{tabular}{llllr}
\hline Variables & $\begin{array}{l}\text { Group I } \\
\text { (PAH-CHD) }\end{array}$ & $\begin{array}{l}\text { Group II } \\
(\text { CHD })\end{array}$ & Control group & $P$ value \\
\hline RV FAC & $34.9 \pm 5$ & $38.8 \pm 5.2$ & $40.4 \pm 2.8$ & 0.002 \\
RV E/A ratio & $1 \pm 0.2$ & $1.3 \pm 0.1$ & $1.4 \pm 0.2$ & $<0.001$ \\
RVD (mm) & $38 \pm 4$ & $30 \pm 3$ & $28 \pm 2$ & 0.01 \\
LV FS (\%) & $36.1 \pm 2.1$ & $36.9 \pm 3.4$ & $37.5 \pm 1.3$ & 0.090 \\
mPAP (mmHg) & $48(30-77)$ & $18(16-18)$ & $14(13-16)$ & $<0.001$ \\
\hline
\end{tabular}

$R V F A C$ right ventricular fractional area change, $R V D$ right ventricular diameter, $L V F S$ left ventricular fraction shortening, $m P A P$ mean pulmonary artery pressure
Table 1 Demographic, clinical, and laboratory data of the studied groups

\begin{tabular}{llllr}
\hline Variables & $\begin{array}{l}\text { Group I } \\
\text { (PAH-CHD) }\end{array}$ & $\begin{array}{l}\text { Group II } \\
\text { (CHD) }\end{array}$ & Control group & P value \\
\hline Age (months) & $5.5(3-16)$ & $3.5(2-14)$ & $9(6-21)$ & 0.058 \\
Sex (male:female) & $32: 28$ & $40: 20$ & $26: 34$ & 0.191 \\
Weight (kg) & $6.3(5-8)$ & $5.5(4-10)$ & $9(8-12)$ & 0.001 \\
HR (beats/min) & $128.2 \pm 19.3$ & $118.2 \pm 17.9$ & $90.6 \pm 16.7$ & 0.001 \\
RR (cycle/min) & $40.6 \pm 4.6$ & $40.7 \pm 4.6$ & $37.5 \pm 4.5$ & 0.01 \\
O sat (\%) & $96(94-97)$ & $92(85-98)$ & $98(96-98)$ & 0.001 \\
Platecrit (\%) & $0.36 \pm 0.13$ & $0.25 \pm 0.07$ & $0.20 \pm 0.06$ & $<0.001$ \\
MPV (FL) & $10.19 \pm 1.44$ & $8.80 \pm 0.73$ & $8.42 \pm 0.98$ & $<0.001$ \\
PDW (FL) & $13.20 \pm 3.10$ & $9.88 \pm 1.39$ & $9.76 \pm 1.35$ & \\
Diagnosis: N (\%) & & & & \\
VSD & $20(33.3 \%)$ & $15(25 \%)$ & & \\
VSD+ASD & $14(23.3 \%)$ & $10(16.7 \%)$ & & \\
VSD+PDA & $6(10 \%)$ & $3(5 \%)$ & & \\
VSD+MR & $2(3.3 \%)$ & $1(1.7 \%)$ & \\
VSD+PS & $0(0 \%)$ & $6(10 \%)$ & & \\
ASD & $2(3.3 \%)$ & $5(8.3 \%)$ & \\
PDA & $7(11.7 \%)$ & $6(10 \%)$ & \\
TGA & $5(8.3 \%)$ & $6(10 \%)$ & \\
TOF & $0(0 \%)$ & $6(10 \%)$ & \\
AVC & $4(6.7 \%)$ & $2(3.3 \%)$ & \\
\hline
\end{tabular}

$H R$ heart rate, $R R$ respiratory rate, $M P V$ mean platelet volume, $P D W$ platelet distribution width, $V S D$ ventricular septal defect, $A S D$ atrial septal defect, $P D A$ patent ductus arteriosus, $M R$ mitral regurge, $P S$ pulmonary stenosis, $T G A$ transposition of great arteries, TOF tetralogy of Fallot, $A V C$ atrioventricular canal 
Table 3 Platelet activation markers in different grades of PH in group I

\begin{tabular}{rlccc}
\hline Parameter & $\begin{array}{l}\text { Mild PH } \\
(n=22)\end{array}$ & $\begin{array}{l}\text { Moderate PH } \\
(n=18)\end{array}$ & $\begin{array}{l}\text { Severe PH } \\
(n=20)\end{array}$ & $P$ \\
\hline Platecrit (\%) & $\begin{array}{l}0.32 \pm 0.08 \\
\text { PostHoc test }\end{array}$ & $\begin{array}{l}\text { Mild vs moderate }=0.149 \pm 0.17 \\
\text { severe }=0.001, \text { moderate versus severe }=0.001\end{array}$ & $0.54 \pm 0.16$ & 0.001 \\
MPV (FL) & $\begin{array}{l}9.9 \pm 1.1 \\
\text { PostHoc test }\end{array}$ & $\begin{array}{l}\text { Mild vs moderate }=0.819, \text { mild versus } \\
\text { severe }=0.002, \text { moderate versus severe }=0.009\end{array}$ \\
PDW (FL) & $\begin{array}{l}12.1 \pm 2.2 \\
\text { 13.2 } \pm 2.1\end{array} \quad 18.6 \pm 3.7$ & $<0.001$ \\
PostHoc test & $\begin{array}{l}\text { Mild vs moderate }=0.936, \text { mild versus } \\
\text { severe }=0.004, \text { moderate versus severe }=0.005\end{array}$ \\
\hline
\end{tabular}

$P H$ pulmonary hypertension, $M P V$ mean platelet volume, $P D W$ platelet distribution width

There was a statistically significant positive correlation between MPV with RV diameter and mPAP while there was a statistically significant negative correlation between MPV with RV FAC, $\mathrm{RV} E / A$ ratio, and $\mathrm{O}_{2}$ saturation. There was a statistically significant positive correlation between PDW with RV diameter and mPAP while there was a statistically significant negative correlation between PDW with RV FAC, RV E/A ratio, and DBP. Moreover, there was a statistically significant positive correlation between platecrit with RV diameter and mPAP, while there was a statistically significant negative correlation between platecrit with RV FAC, $\mathrm{RV}$ E/A ratio, and $\mathrm{O}_{2}$ saturation (Table 4).

During the period of follow-up, 8 out of 60 patients with PAH-CHD had unfavourable prognoses in the form of death and readmission due to right ventricular heart failure. Platelet activation markers levels were significantly higher in children with a poor prognosis compared to patients with good prognosis (Table 5).
Table 5 Platelet indices in children with CHD-PH with good and bad prognosis on follow-up

\begin{tabular}{lrrr}
\hline Parameters & \multicolumn{1}{l}{ Prognosis } & \multicolumn{1}{l}{$P$} \\
\cline { 2 - 3 } & \multicolumn{1}{l}{ Good $(n=52)$} & \multicolumn{1}{c}{ Poor $(n=8)$} & \\
\hline Platecrit (\%) & $0.32 \pm 0.09$ & $0.58 \pm 0.10$ & $<0.001$ \\
MPV (FL) & $9.83 \pm 1.15$ & $12.50 \pm 0.96$ & 0.005 \\
PDW (FL) & $12.47 \pm 2.35$ & $17.95 \pm 3.50$ & 0.04 \\
\hline
\end{tabular}

$M P V$ mean platelet volume, $P D W$ platelet distribution width

MPV at a cut-off $>11.2$ FL showed a $75 \%$ sensitivity and $96.6 \%$ specificity to predict a poor prognosis in children with PAH-CHD, while PDW at a cut-off $>12.7$ FL showed a $75 \%$ sensitivity and $61.5 \%$ specificity to predict a poor prognosis in children with PAH-CHD. Platecrit at cut-off $>0.505 \%$ showed a $75 \%$ sensitivity and $93 \%$ specificity to predict a poor prognosis in children with PAH-CHD. (Fig. 1).

\section{Discussions}

PAH affects the course of CHDs, morbidity, and mortality in many children. Therefore, early recognition of high risk patients with $\mathrm{PH}$ who need more aggressive treatment is crucial. Many biomarkers have been implicated in the prognosis of PH in children with PAH-CHD but the search for the ideal biomarker is still going $[18,19]$.

In the current study, we found that the median values of platecrit, MPV, and PDW were significantly elevated in children with PAH-CHD compared to children with CHD and the control group. A similar result was observed by Zheng et al. [12] who reported that MPV and PDW were significantly higher in patients with idiopathic $\mathrm{PH}$ compared to the control group. Moreover, Kaya et al. [13] found that MPV
Table 4 Correlation between platelet activation markers and different parameters in group I

\begin{tabular}{|c|c|c|c|c|c|c|}
\hline \multirow[t]{2}{*}{ Parameters } & \multicolumn{2}{|c|}{ MPV (FL) } & \multicolumn{2}{|c|}{ PDW (FL) } & \multicolumn{2}{|c|}{ Platecrit (\%) } \\
\hline & $r$ & $P$ & $R$ & $P$ & $r$ & $P$ \\
\hline Age (months) & 0.184 & 0.332 & 0.259 & 0.168 & 0.007 & 0.971 \\
\hline Weight (kg) & 0.272 & 0.146 & 0.197 & 0.296 & 0.003 & 0.989 \\
\hline HR (beats/min) & -0.234 & 0.212 & 0.099 & 0.603 & 0.186 & 0.325 \\
\hline RR (cycle/min) & 0.039 & 0.839 & 0.214 & 0.256 & 0.398 & 0.029 \\
\hline $\mathrm{O}_{2}$ saturation $(\%)$ & -0.627 & $<0.001$ & -0.330 & 0.075 & -0.388 & 0.034 \\
\hline LV FS (\%) & -0.121 & 0.523 & -0.264 & 0.158 & -0.249 & 0.184 \\
\hline RVD (cm) & 0.532 & 0.002 & 0.593 & 0.001 & 0.615 & $<0.001$ \\
\hline RV FAC & -0.600 & $<0.001$ & -0.410 & 0.024 & -0.469 & 0.009 \\
\hline RV E/A ratio & -0.463 & 0.010 & $-0.606^{*}$ & $<0.001$ & -0.659 & $<0.001$ \\
\hline mPAP (mmHg) & 0.598 & $<0.001$ & 0.646 & $<0.001$ & 0.697 & $<0.001$ \\
\hline
\end{tabular}

$M P V$ mean platelet volume, $P D W$ platelet distribution width, $H R$ heart rate, $R R$ respiratory rate, $R V D$ right ventricular diameter, $R V F A C$ right ventricular fractional area change, $L V F S$ left ventricular fraction shortening, $m P A P$ mean pulmonary artery pressure 


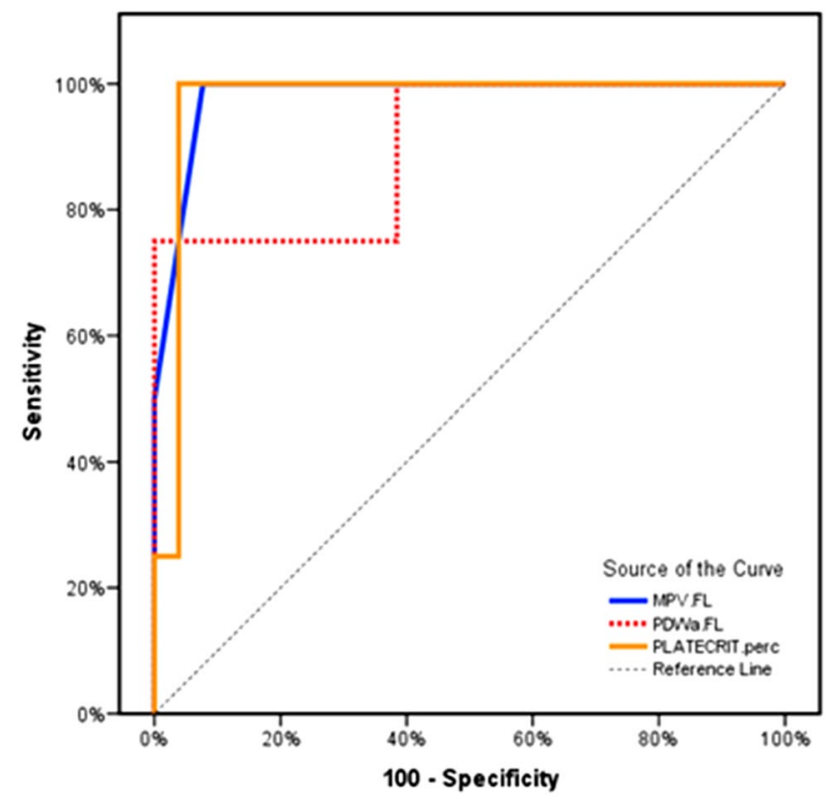

Fig. 1 ROC curve showed that MPV at a cut-off $>11.2$ FL had a sensitivity of $75 \%$ and a specificity of $96.6 \%$, PDW at a cut-off $>12.7$ FL had a sensitivity of $75 \%$ and a specificity of $61.5 \%$, and platecrit at cut-off $>0.505 \%$ had a sensitivity of $75 \%$ and a specificity of $93.2 \%$ to predict a poor prognosis in children with $\mathrm{PAH}-\mathrm{CHD}$

was significantly higher in patients with ASD and PAH. Mese et al. [15] reported higher MPV, PDW, and platecrit in children with PAH-CHD compared to the healthy control group.

MPV, PDW, and platecrit are simple hematological markers of assessing platelet function and activity and easily available [12]. Larger platelets, which are more active than smaller ones, might contribute to thrombosis that is involved in the pathogenesis of PAH [20, 21]. The pathogenesis of PAH is complex and includes vascular remodelling, vasoconstriction, inflammation, and microthrombosis [22]. Elevated platelet activation markers levels in children with PAH-CHP in our study suggested increased procoagulant activity and platelet activation [23, 24]. Besides, systemic inflammatory cytokines such as interleukin-3 (IL-3) and IL- 6 were found to be increased in patients with PAH which may affect megakaryopoiesis, and leads to larger and more reactive platelets, therefore, an increase in the platelet activation indices [25].

In contrast to our study, Arslan et al. [14] showed that MPV and PDW were lower in children with PAH. This discrepancy may in part due to small sample size of their study and different patient characteristics and hemodynamic data.

PAH-CHD is associated with poor prognosis in children. New non-invasive biomarkers are needed to help classify and assess the risk stratification of PAH-CHD. We reported that platelet activation markers levels were strongly associated with increasing severity of PAH, being the highest in children with severe PAH and the lowest in children with mild PAH denoting that it may have a role in the pathogenesis of PAH. Moreover, there was a statistically significant positive correlation between MPV, PDW and platecrit levels with mPAP and RVD suggesting a pathological role that is directly linked to the increased pressure in pulmonary vasculature. These results were consistent with the results of previous studies [13, 15, 26, 27].

Furthermore, there was a statistically significant negative correlation between MPV, PDW and platecrit levels with RV $E / A$ ration and RV FAC ratio which represented diastolic and systolic function of the RV. All of which being indicators of more severe disease and poor outcome in PAH patients [25, 26]. Activated sympathetic nervous system in RV failure could contribute to the activation of platelets through activation of platelet factor 4 and beta-thromboglobulin, which are markers of platelet activation [28].

Our results showed higher PDW, MPV, and platecrit in children with poor prognosis compared to those with good prognosis. In agreement with our results, increased MPV, PDW and platecrit levels were found to be associated with a higher risk of death and an independent predictor of poor outcome and 12 months' survival among patients with PAH $[12,15]$. Moreover, MPV, PDW, and platecrit levels have been shown to be of prognostic importance in a variety of cardiovascular pathologies [23, 29]. Therefore, elevated MPV, PDW and platecrit levels could add important prognostic information that could not be known by right heart catheterization alone.

Furthermore, MPV at a cut-off $>11.2$ FL showed a $75 \%$ sensitivity and $96.6 \%$ specificity to predict a poor prognosis in children with PAH-CHD, while PDW at a cut-off $>12.7$ FL showed a $75 \%$ sensitivity and $61.5 \%$ specificity to predict a poor prognosis in children with PAH-CHD. Platecrit at cut-off $>0.505 \%$ showed a $75 \%$ sensitivity and $93.2 \%$ specificity to predict a poor prognosis in children with PAH-CHD.

Currently, hemodynamic parameters are key indicators for assessing progression and prognosis of $\mathrm{PAH}$, but alternative non-invasive quick reliable biomarkers to monitor disease severity and prognosis are urgently needed in children with PAH-CHD. Our study reported MPV, PDW, and platecrit as good prognostic biomarkers for adverse outcome in children with PAH-CHD. They are simple biomarkers which can be measured by automated hematology analyzer. They are easily accessible, cheap and don't need advanced technology.

Limitations of the study include a small sample size of included children, being a single-center study, and short duration of follow-up. Use of echocardiography for diagnosis of PAH-CHD instead of cardiac catheterization could be another limitation of the study, however several studies reported that non-invasive echocardiographic diagnosis of $\mathrm{PH}$ correlated well with the results of cardiac catheterization 
$[30,31]$. Further investigations are needed to understand the role of platelet activation in patients with $\mathrm{PAH}-\mathrm{CHD}$. Also, more studies with larger sample size are needed to confirm these results.

\section{Conclusion}

MPV, PDW, and platecrit were elevated in children with PAH-CHD and its levels correlated to the severity of PAH. Higher MPV, PDW, and platecrit levels on admission could be used as a promising biomarker to identify PAH-CHD children with poor prognosis who need more aggressive treatment.

Author Contributions AA: acquisition of data, following up the patients, analysis and interpretation of data, drafting and final approval of the manuscript. DEA: idea of the research, doing the echocardiography, drafting and final approval of the manuscript. SE: acquisition of data, following up the patients, drafting and final approval of the manuscript. HH: doing the laboratory tests, drafting and final approval of the manuscript.

Funding Open access funding provided by The Science, Technology \& Innovation Funding Authority (STDF) in cooperation with The Egyptian Knowledge Bank (EKB).

Data Availability Available when required.

Code Availability Not applicable.

\section{Declarations}

Conflict of interest The authors declare that they have no conflict of interest.

Ethical Approval Local ethics committee of Faculty of Medicine, Tanta University approved the study.

Consent to Participate An informed consent was obtained from the parents of all subjects of the study before enrollment.

Consent to Publication All the authors transfer, assign, or otherwise convey all copyright ownership, including any and all rights exclusively to the journal, in the event that such work is published by the journal.

Open Access This article is licensed under a Creative Commons Attribution 4.0 International License, which permits use, sharing, adaptation, distribution and reproduction in any medium or format, as long as you give appropriate credit to the original author(s) and the source, provide a link to the Creative Commons licence, and indicate if changes were made. The images or other third party material in this article are included in the article's Creative Commons licence, unless indicated otherwise in a credit line to the material. If material is not included in the article's Creative Commons licence and your intended use is not permitted by statutory regulation or exceeds the permitted use, you will need to obtain permission directly from the copyright holder. To view a copy of this licence, visit http://creativecommons.org/licenses/by/4.0/.

\section{References}

1. Dolk H, Loane M, Garne E (2011) Congenital heart defects in Europe: prevalence and perinatal mortality, 2000 to 2005. Circulation 123(8):841-849

2. Barst RJ, McGoon M, Torbicki A, Sitbon O, Krowka MJ, Olschewski H, Gaine S (2004) Diagnosis and differential assessment of pulmonary arterial hypertension. JACC 43(12 Supplement):S40-S47

3. Galiè N, Humbert M, Vachiery JL, Gibbs S, Lang I, Torbicki A, Simonneau G, Peacock A, Vonk Noordegraaf A, Beghetti M, Ghofrani A, Gomez Sanchez MA, Hansmann G, Klepetko W, Lancellotti P, Matucci M, McDonagh T, Pierard LA, Trindade PT, Zompatori M, Hoeper M (2015) ESC/ERS guidelines for the diagnosis and treatment of pulmonary hypertension: the joint task force for the diagnosis and treatment of pulmonary hypertension of the European Society of Cardiology (ESC) and the European Respiratory Society (ERS): endorsed by: Association for European Paediatric and Congenital Cardiology (AEPC), International Society for Heart and Lung Transplantation (ISHLT). EHJ 37(1):67-119

4. Gaheen R, El Amrousy D, Hodeib H, Elnemr S (2021) Plasma copeptin levels in children with pulmonary arterial hypertension associated with congenital heart disease. Eur J Pediatr 180:2889-2895

5. Abman SH, Hansmann G, Archer SL, Ivy DD, Adatia I, Chung WK, Hanna BD, Rosenzweig EB, Raj JU, Cornfield D, Stenmark KR, Steinhorn R, Thébaud B, Fineman JR, Kuehne T, Feinstein JA, Friedberg MK, Earing M, Barst RJ, Keller RL, Kinsella JP, Mullen M, Deterding R, Kulik T, Mallory G, Humpl T, Wessel DL (2015) Pediatric pulmonary hypertension: guidelines from the American heart association and American thoracic society. Circulation 132(21):2037-2099

6. Farag M, El Amrousy D, El-Serogy H, Zoair A (2018) Role of plasma asymmetric dimethyl-L-arginine levels in detection of pulmonary hypertension in children with CHD. Cardiol Young 28(9):1163-1168

7. Sakao S, Tatsumi K (2011) Vascular remodeling in pulmonary arterial hypertension: multiple cancerlike pathways and possible treatment modalities. Int J Cardiol 147:4-12

8. Dow RB (1994) The clinical and laboratory utility of platelet volume parameters. Aust J Med Sci 15:12-15

9. Park Y, Schoene N, Harris W (2002) Mean platelet volume as an indicator of platelet activation: methodological issues. Platelets 13(5-6):301-306

10. Nadar S, Blann AD, Lip GY (2004) Platelet morphology and plasma indices of platelet activation in essential hypertension: effects of amlodipine based antihypertensive therapy. Ann Med 36(7):552-557

11. Sakamaki F, Kyotani S, Nagaya N, Sato N, Oya H, Satoh T, Nakanishi N (2000) Increased plasma P-selectin and decreased thrombomodulin in pulmonary arterial hypertension were improved by continuous prostacyclin therapy. Circulation 102(22):2720-2725

12. Zheng YG, Yang T, Xiong CM, He JG, Liu ZH, Gu Q, Zhao ZH, Ni XH (2015) Platelet distribution width and mean platelet volume in idiopathic pulmonary arterial hypertension. Heart Lung Circ 24(6):566-572

13. Kaya MG, Elcik D, Akpek M, Kelesoglu S, Sahin O, Sarli B, Lam YY (2014) Mean platelet volume levels predict pulmonary artery hypertension in patients with atrial septal defect. Acta Cardiol 69(2):161-166

14. Arslan D, Cimen D, Guvenc O, Kaya F, Sert A, Oran B (2013) Platelet distribution width and mean platelet volume in children with pulmonary arterial hypertension secondary to congenital 
heart disease with left-to-right shunt: new indices of severity? Pediatr Cardiol 34:1013-1016

15. Mese T, Guven B, Yilmazer MM, Karadeniz C, Ozdemir R, Doksoz O (2018) Platelet activation markers in children with congenital heart disease associated with pulmonary arterial hypertension. Congenit Heart Dis 13:506-511

16. DiLorenzo MP, Bhatt SM, Mercer-Rosa L (2015) How best to assess right ventricular function by echocardiography. Cardiol Young 25(8):1473-1481

17. Galiè N, Hoeper MM, Humbert M, Torbicki A, Vachiery J, Barbera JA, Beghetti M, Corris P, Gaine S, Gibbs JS, Gomez-Sanchez MA, Jondeau G, Klepetko W, Opitz C, Peacock A, Rubin L, Zellweger M, Simonneau G (2009) Guidelines for the diagnosis and treatment of pulmonary hypertension: the Task Force for the Diagnosis and Treatment of Pulmonary Hypertension of the European Society of Cardiology (ESC) and the European Respiratory Society (ERS), endorsed by the International Society of Heart and Lung Transplantation (ISHLT). Eur Heart J 30:2493-2537

18. Hella E, El Amrousy D, El-Serogy H, Zoair A (2020) Diagnostic and predictive values of plasma connective tissue growth factor in children with pulmonary hypertension associated with CHD. Cardiol Young 30(4):533-538

19. El Amrousy D, Zahran E, El-Serogy H, Zoair A (2020) Plasma growth differentiation factor- 15 in children with pulmonary hypertension associated with congenital heart disease: a canary in the mine? Progr Pediatr Cardiol 59:101206

20. Kamath S, Blann AD, Lip GY (2001) Platelet activation: assessment and quantification. Eur Heart J 22(17):1561-1571

21. Balbaloglu O, Korkmaz M, Yolcu S (2014) Evaluation of mean platelet volume (MPV) levels in patients with synovitis associated with knee osteoarthritis. Platelets 25(2):81-85

22. Schermuly RT, Ghofrani HA, Wilkins M, Grimminger F (2011) Mechanisms of disease: pulmonary arterial hypertension. Nat Rev Cardiol 8(8):443

23. Berger G, Azzam ZS, Hoffman R (2009) Coagulation and anticoagulation in pulmonary arterial hypertension. Isr Med Assoc J 11(6):376-379

24. Varol E, Uysal BA, Ozaydin M (2011) Platelet indices in patients with pulmonary arterial hypertension. Clin Appl Thromb Hemost 17(6):E171-E174
25. Harrison S, Vavken P, Kevy S, Jacobson M, Zurakowski D, Murray MM (2011) Platelet activation by collagen provides sustained release of anabolic cytokines. Am J Sports Med 39:729-734

26. Benza RLL, Miller DP, Romberg-Maitland M, Frantz RP, Foreman AJ, Coffey CS, Frost A, Barst RJ, Badesch DB, Elliott CG, Liou TG, McGoon MD (2010) Predicting survival in pulmonary arterial hypertension insights from the Registry to Evaluate Early and Long-Term Pulmonary Arterial Hypertension Disease Management (REVEAL). Circulation 122(2):164-172

27. Barst RJ, McGoon MD, Elliott CG, Foreman AJ, Miller DP, Ivy DD (2012) Survival in childhood pulmonary arterial hypertension: insights from the registry to evaluate early and long-term pulmonary arterial hypertension disease management. Circulation 125(1):113-122

28. Can MM, Tanboga IH, Demircan HC, Ozkan A, Koca F, Keleş N, Sönmez K, Kaymaz C, Serebruany V (2010) Enhanced hemostatic indices in patients with pulmonary arterial hypertension: an observational study. Thromb Res 126(4):280-282

29. Jafri SM, Ozawa T, Mammen E, Levine TB, Johnson C, Goldstein S (1993) Platelet function, thrombin and fibrinolytic activity in patients with heart failure. Eur Heart J 14:205-212

30. Greiner S, Jud A, Aurich M, Hess A, Hilbel T, Hardt S, Katus HA, Mereles D (2004) Reliability of noninvasive assessment of systolic pulmonary artery pressure by Doppler echocardiography compared to right heart catheterization: analysis in a large patient population. J Am Heart Assoc 3(4):e001103

31. Lafitte S, Pillois X, Reant P, Picard F, Arsac F, Dijos M, Coste P, Dos Santos P, Roudaut R (2013) Estimation of pulmonary pressures and diagnosis of pulmonary hypertension by Doppler echocardiography: a retrospective comparison of routine echocardiography and invasive hemodynamics. J Am Soc Echocardiogr 26(5):457-463

Publisher's Note Springer Nature remains neutral with regard to jurisdictional claims in published maps and institutional affiliations. 